\title{
Investigation of the Thermal Performance of Energy Tunnel Equipped with the Insulation Layer Considering Ventilation and Groundwater Seepage
}

\author{
Guozhu Zhang $\mathbb{D}^{1,2}$ Ziming Cao ${ }^{1},{ }^{1,2}$ Xu Zhao, ${ }^{3}$ Yongli Xie, ${ }^{4}$ Xiaohua Liu, ${ }^{4}$ and Shiding Cao ${ }^{4}$ \\ ${ }^{1}$ Institute of Geotechnical Engineering, Southeast University, Nanjing 211189, China \\ ${ }^{2}$ Jiangsu Key Laboratory of Urban Underground Engineering \& Environmental Safety, Southeast University, Nanjing 211189, China \\ ${ }^{3}$ Key Laboratory of Urban Security and Disaster Engineering of Ministry of Education, Beijing University of Technology, \\ Beijing 100124, China \\ ${ }^{4}$ Shenzhen Transportation Design \& Research Institute Co., Ltd., Shenzhen 518003, China
}

Correspondence should be addressed to Guozhu Zhang; zhanggz@seu.edu.cn

Received 25 May 2021; Accepted 10 July 2021; Published 9 August 2021

Academic Editor: Huie Chen

Copyright ( 2021 Guozhu Zhang et al. This is an open access article distributed under the Creative Commons Attribution License, which permits unrestricted use, distribution, and reproduction in any medium, provided the original work is properly cited.

\begin{abstract}
The insulation layer is usually installed in the tunnel structure, whereas the influence of the insulation layer on the thermal behavior of energy tunnel ground heat exchangers (GHEs) is rarely investigated. The model tests were performed in this study to evaluate the heat transfer potential of the energy tunnel with the insulation layer under ventilation and groundwater seepage. The results can be obtained as follows: first, the fluctuations of air temperature and surrounding rock temperature at different locations are relevant to insulation layer, ventilation, and groundwater seepage. Second, the reduction effect of ventilation on the interface temperature of tunnel lining and surrounding rock is alleviated when using an insulation layer, and the interface temperature at upstream section of groundwater seepage is more easily affected by the energy tunnel GHEs. Third, the variation range of ground temperature is wider at the downstream section of groundwater flow. Moreover, the heat exchange rates of tunnel without the insulation layer improve by $5.82 \%$ and $6.45 \%$ with increasing wind speed at two groundwater flow velocities of $1 \times 10^{-4}$ and $5 \times 10^{-4} \mathrm{~m} / \mathrm{s}$, and there are only $2.03 \%$ and $0.77 \%$ enhancements of heat exchange rates by ventilation for the tunnel with the insulation layer. However, the thermal performance of the energy tunnel improved by groundwater is less relevant to the existence of the insulation layer. The relevant findings can provide an effective guidance for the following research and design of the energy tunnel.
\end{abstract}

\section{Introduction}

With the development of energy geotechnical engineering, many studies are being conducted worldwide to apply the ground source heat pump (GSHP) technology in the construction of underground structures [1-3]. The investigations regarding the energy geostructures (e.g., diaphragm walls, foundations, and tunnels) have attracted the attention of many scholars, and the corresponding achievements also have displayed a remarkable increasing trend [3-9]. The technology combining the GSHP system with the tunnel engineering is defined as the energy tunnel technology.
Recently, the investigations on the energy tunnels have generated a lot of interest, and the energy tunnel technology has been introduced in different countries such as Austria, Germany, Italy, China, and South Korea.

The ground heat exchangers (GHEs) can be installed in the different positions of the energy tunnel (e.g., GHEs arranged in rock bolt [1], at the tunnel invert [2], between primary lining and secondary lining $[9,10]$, and within the prefabricated tunnel lining segment [11]) to extract or inject the heat amount from or into the surrounding rock and realize the purpose of the heating or cooling for the tunnel and nearby buildings. Different performances of the GHEs 


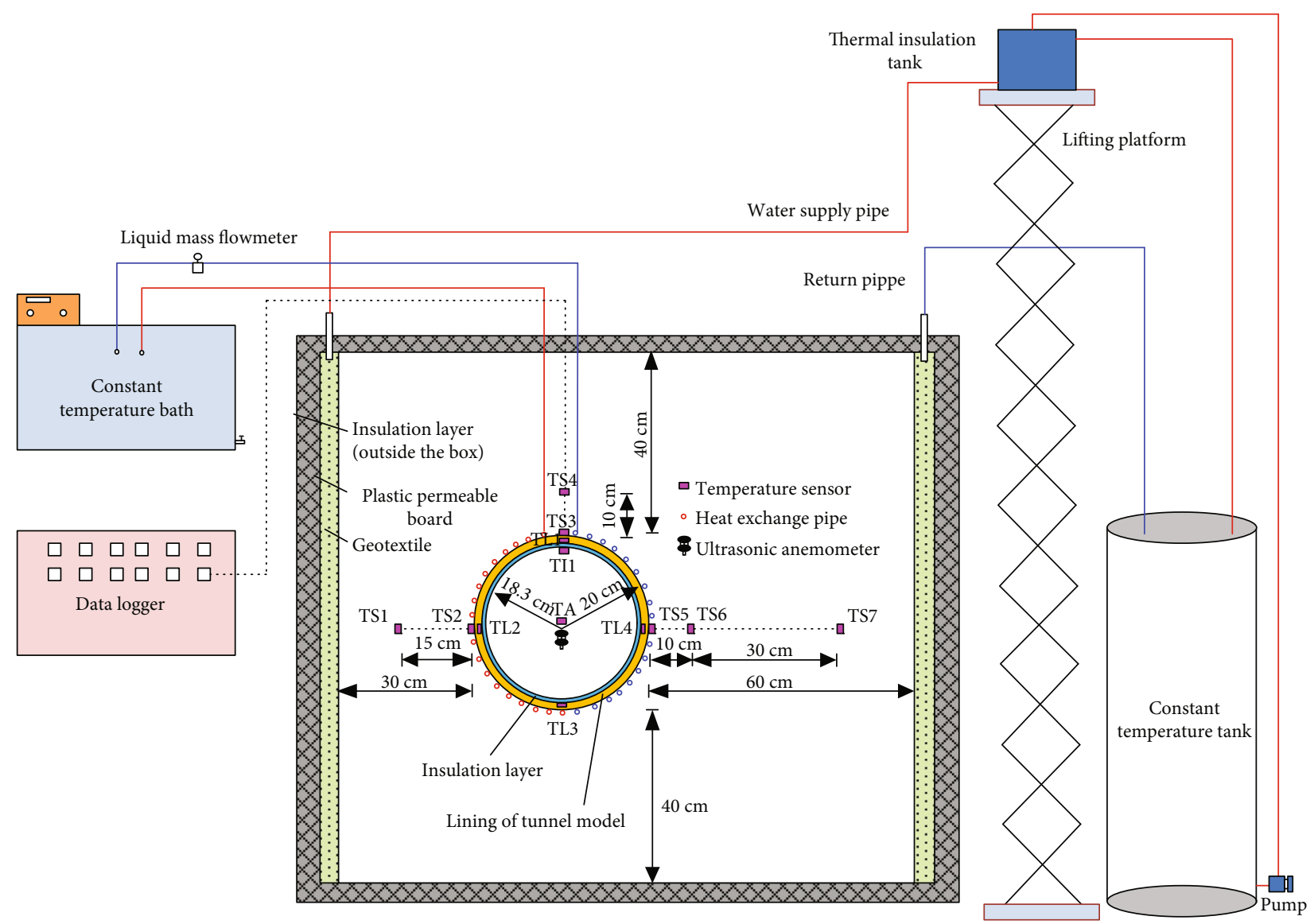

(a) Transverse section

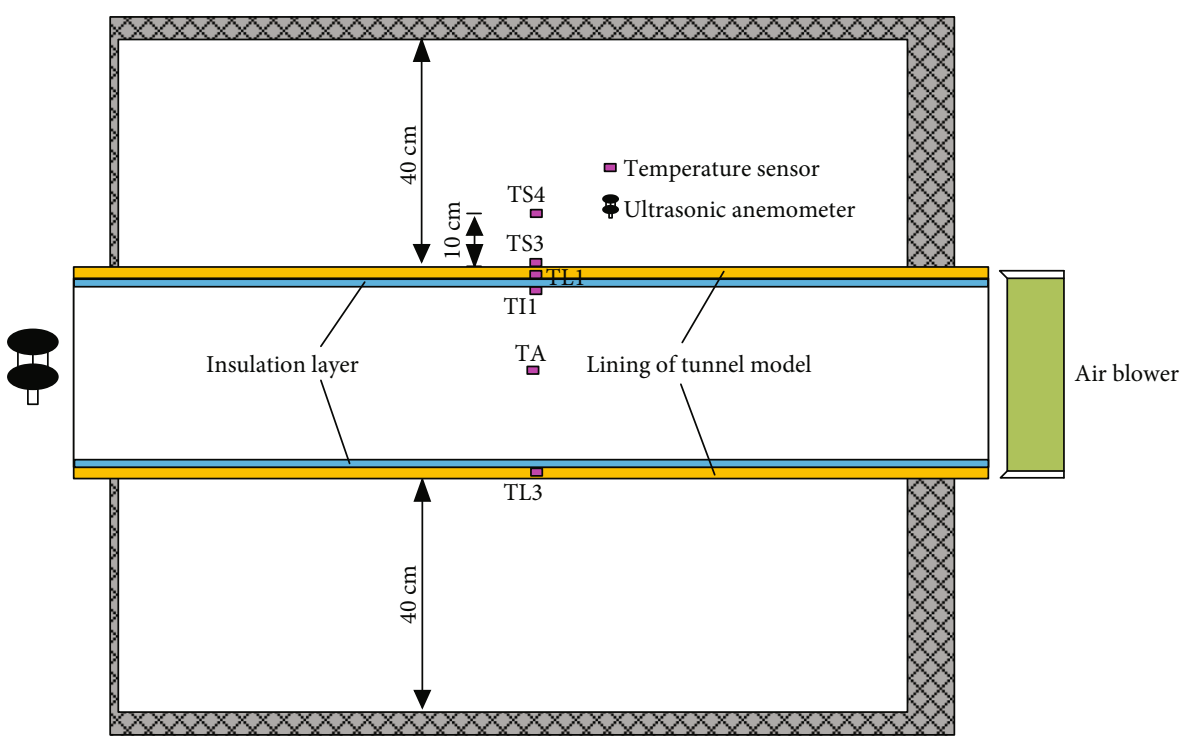

(b) Longitudinal section

Figure 1: Schematic diagram of the tunnel model test system.

installed in the energy tunnels have been investigated through field experiments, numerical simulations, laboratory model tests, and theoretical analyses [1, 2, 9-19]. Brandl [1] firstly proposed the application of the energy tunnel technology in a tunnel project in Austria. Adam and Markiewicz [2] selected the energy geotextiles (composed of GHEs) to install between tunnel primary lining and secondary lining in the experimental section of Lainzer tunnel and found that the energy tunnel had a good operation effect. Zhang et al. [9, 20] established the heat transfer model and adopted some theoretical analysis methods of superposition principle, Laplace transform, and finite integral transform method to 
optimize and analyze the heat transfer mechanism of the energy tunnel GHE system and find the analytical solutions for the temperature field of heat absorbing section of GSHP system in the cold-region tunnel. Barla et al. [11, 12] came up with an idea of the promotion of the energy tunnel to urban environments in Italy and performed the field experiments of heat exchangers in the segmental lining of the energy tunnel in the South extension of the Metro Torino line 1. Lee et al. $[13,21]$ carried out a series of laboratory tests, field experiments, and numerical simulations to study the thermal behaviors of energy textiles arranged in the tunnel. It can be found from their studies that the application of energy textiles in tunnel was considered as an innovative method for the geothermal energy utilization, whereas the optimal design of energy textiles remained to be further investigated. Franzius and Pralle [14] proposed a novel energy tunnel lining system with heat exchanger segments to apply in a full-face TBM tunnel in Germany and found that this new lining system was useful. Besides, this new energy tunnel lining system was applied in a new highspeed railway Jenbach tunnel of Austria [15]. Cousin et al. [16] evaluated the extracted thermal power ability and feasibility of the metro tunnels with the heat exchanger segments by using various approaches of the finite element analysis, cost analysis, and profitability assessment method. The results of Ogunleye et al. [22] indicated that the reasonable intermittent operation could improve the thermal efficiency of the energy tunnel, restore heat to the surrounding soil, and prevent the generation of detrimental effects. Simultaneously, they also found that the thermal behaviors of energy tunnel were affected by the air temperature inside the tunnel. In addition, Insana and Barla [23] found that the direction of groundwater seepage, flow rate of circulating fluid, inlet temperature of circulating fluid, and sizes of pipe could impact the thermal performance and efficiency of the energy tunnel GHE system. Mimouni et al. [24] used the anchors as the heat exchangers in a cut-and-cover tunnel and analyzed the effects of different influencing factors of soil properties, water table level, and service thermal loads on the geothermal potential of heat exchanger anchors within the energy tunnel. Their results presented that the performance of heat exchanger anchors in the tunnel was preferable. Zhang et al. [10, 2528] conducted the field experiments, laboratory model tests, and numerical simulations to investigate the influences of various parameters (e.g., inlet water temperature, flow rate, pipe spacing, operation time, ventilation, and groundwater seepage) on the thermal responses of the energy tunnel GHEs. Bidarmaghz and Narsilio [29] developed a 3D numerical model to study the influences of groundwater flow and airflow inside the tunnel on the heat exchange mechanism of the energy tunnel system and found that the groundwater seepage and tunnel airflow affected the ground temperature field and thermal behaviors of the energy tunnel GHEs. Based on the previous research results, the tunnel ventilation and groundwater seepage condition are important factors to influence the thermal performance and efficiency of the energy tunnel GHEs. Thus, the parameters of tunnel ventilation and groundwater seepage need to be considered in the investigation and design of the energy tunnel.

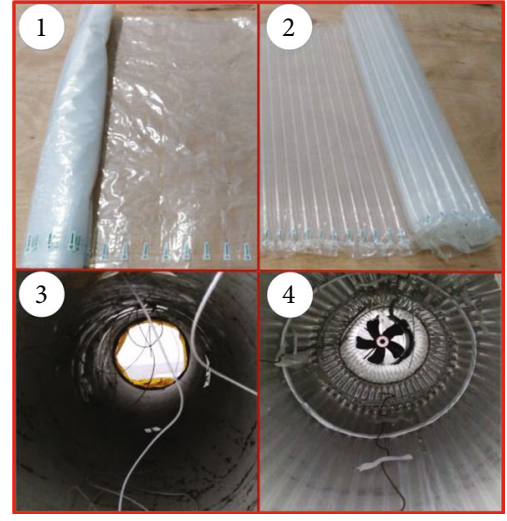

FIgURE 2: Manufacturing process of the insulation layer for the energy tunnel.

Up to now, the researches concerning the thermal transfer mechanisms of the energy tunnel equipped with the insulation layer is relatively rare. Many scholars have employed the different methods (e.g., field tests, numercial simulations, and model tests) to analyze the heat transfer characteristic and temperature field variation of the tunnel equipped with the insulation layer and evaluate the function of the insulation layer inside the tunnel [30-36]. The installation of the insulation layer within the tunnel can directly affect the variation trend of the tunnel temperature fields. Generally, the design of the insulation layer is an important step during the whole process of tunnel construction and operation [30, $31,33,35]$. Accordingly, the influence of the insulation layer on the thermal response of the energy tunnel needs to be further investigated, which is very helpful for the application of energy tunnels in different regions and climatic conditions.

In the current study, the tunnel model experiments were carried out to investigate the influence of the insulation layer on the thermal behaviors of the energy tunnel under ventilation and groundwater seepage. The tunnel air temperture, temperature difference between tunnel lining and airflow, interface temperature of tunnel lining and surrounding rock, ground temperature, outlet temperature of GHEs, and heat transfer capacity of the energy tunnel with or without the insulation layer at different environmental factors (ventilation and groundwater flow) were analyzed and discussed. The relevant research findings can become a guidance for the further development and popularization of the energy tunnel.

\section{Experimental Investigation}

2.1. Fundamental Principle. The thermal response model experiments were performed to study the influence of the insulation layer on the heat transfer behaviors of the energy tunnel under tunnel ventilation and groundwater seepage. The tunnel insulation layer, ventilation, and groundwater seepage are the main influencing factors which need to be considered in the current tests. The fundamental working principle of thermal response experiment of the energy tunnel equipped with the insulation layer is presented in Figure 1. As seen in Figure 1, the whole experimental system 


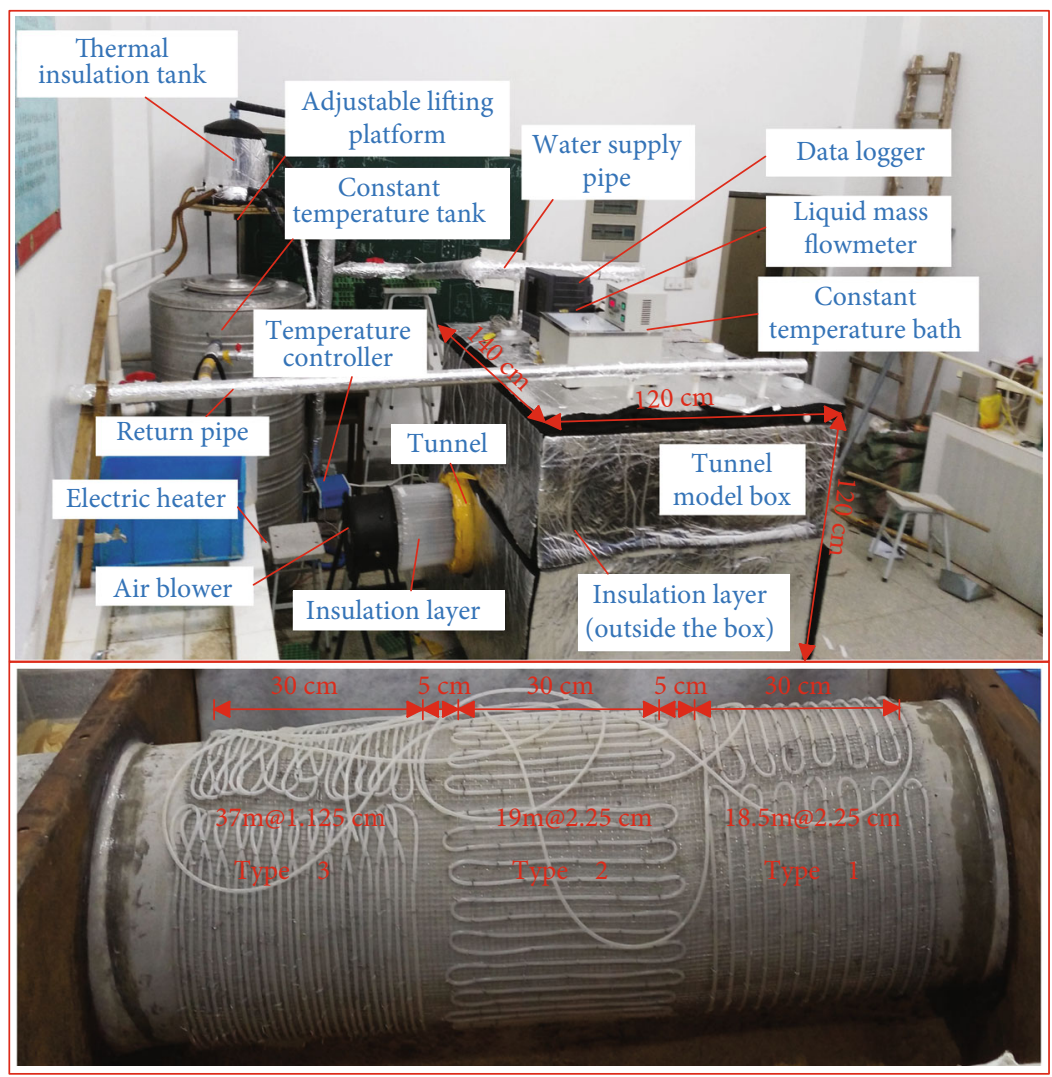

FIGURE 3: Testing equipment used in the laboratory model experiment and layout of heat exchangers on the lining of the energy tunnel model.

TABLE 1: Experimental devices of thermal response model tests for the energy tunnel.

\begin{tabular}{lr}
\hline Experimental devices & Specifications \\
\hline $\begin{array}{l}\text { Thermal insulation tank } \\
\text { Constant temperature tank }\end{array}$ & Maximum water head: 5 m; volume: $18 \mathrm{~L}$. \\
$\begin{array}{l}\text { Constant temperature bath } \\
\text { Air blower }\end{array}$ & Heating power: $6 \mathrm{~kW}$; volume: $1000 \mathrm{~L}$; water head of pump: $9 \mathrm{~m}$; flow velocity: $30 \mathrm{~L} / \mathrm{min}$. \\
$\begin{array}{l}\text { Flow meter } \\
\text { Temperature sensor }\end{array}$ & Accuracy of liquid mass flow meter $(\mathrm{DMF}-1-1-\mathrm{A}): \pm 0.2 \%$; measuring range: $0-40 \mathrm{~kg} / \mathrm{h}$. \\
Ultrasonic anemometer & Accuracy of resistance temperature detector $(\mathrm{HSRTD}-3-100-\mathrm{A}): \pm 0.15^{\circ} \mathrm{C}$.
\end{tabular}

of model tunnel consists of three main parts that is an internal circulation, an external circulation, and a ventilation pipe. For the internal circulation, the heat exchange tubes were placed between lining and surrounding rock, and the heat exchange tubes were connected to the liquid mass flowmeter and the constant temperature bath through the pipes to form the heat exchange system of the energy tunnel. Different constant temperatures of inlet water can be provided by the constant temperature bath. For the external circulation, in order to realize the formation of groundwater flow and underground temperature fields in the tunnel model, the sand box was linked to the thermal insulation tank and the constant temperature tank via different pipes. The thermal insulation tank was arranged at the liftable and lowerable platform. The different seepage velocities of groundwater can be obtained by adjusting the platform height to provide various water heads. The water pump was used to propel the pipeline between thermal insulation tank and constant temperature tank. There is an adjustable electric water heater within the constant temperature tank, which can generate the various constant temperatures. Thus, the various underground temperature fields produced by groundwater seepage in this model study can be simulated. To guarantee the formation of uniform seepage field, two plastic permeable boards were placed at the both sides of the tunnel model box (filled with sand). At the same time, these two boards were covered with the geotextiles to ensure that the sand at the edges of the sand box was not flowed away by the water flow. The ventilation within the model energy tunnel was provided by an air blower, and the wind speed can be regulated by using the voltage of the air blower. The various temperature sensors were used to measure the temperatures of 


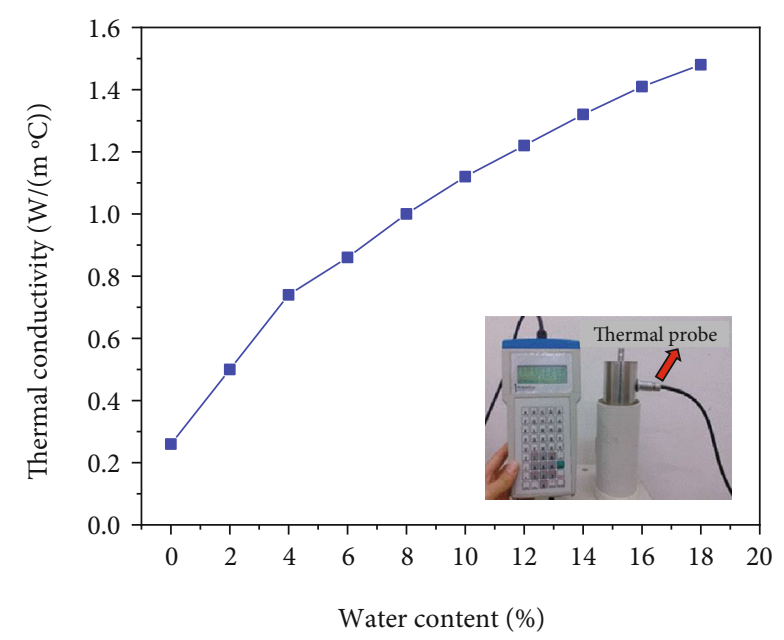

FIGURE 4: Thermal conductivity of experimental sand under various water contents.

surrounding rock (TS), tunnel lining (TL), the internal side of insulation layer (TI), and the air inside tunnel model (TA). The ultrasonic anemometer was employed to measure the wind velocity of the model system. The different velocities of groundwater flow can be obtained by the graduated cylinder $[27,28]$. To minimize or eliminate the thermal influence of ambient air temperature on the model box and guarantee a steady temperature field during the whole tests, the $5 \mathrm{~cm}$-thickness thermal insulation layer was arranged at the external surface of the model box. To investigate the influence of the insulation layer on the thermal response of the energy tunnel, a $10 \mathrm{~mm}$-thickness thermal insulation layer was arranged at the inner side of tunnel lining. The manufacturing process of the insulation layer installed at the inner side of the energy tunnel lining is shown in Figure 2, and the specific manufacturing step is as follows: (1) the rubber bag was selected to prepare the insulation layer, and the dimension of the rubber bag was determined, (2) the rubber bag was filled with air to form an insulation layer, (3) the temperature sensors were installed inside the inner side of the tunnel lining, and (4) the prepared insulation layer was arranged within the tunnel model.

2.2. Testing Equipment and Materials. Figure 3 displays the experimental apparatus applied in this laboratory model experiment and the layout of heat exchangers. The main experimental devices of thermal response model tests and their properties are listed in Table 1.

The tunnel model system was mainly comprised of the stainless steel box and the concrete tube. The dimensions of the box were $1.4 \times 1.2 \times 1.2 \mathrm{~m}$, and the length, external diameter, and thickness of the concrete tube were $1.4 \mathrm{~m}$, $40 \mathrm{~cm}$, and $2 \mathrm{~cm}$, respectively. The concrete tube was a prototype for the 1/20th level actual shield tunnel, which was comprised of cement, sand, gravel, and water with the ratio of $1: 2.4: 3.6: 0.65$. Based on the previous research [28], the geometric similarity ratio of the tunnel was chosen as $1: 20$ to make the similarity between the tunnel model and the real-scale prototype of a shield tunnel. Thus, the tunnel structure was simulated by a concrete tube with $1.4 \mathrm{~m}$ length, $40 \mathrm{~cm}$ external diameter, and $2 \mathrm{~cm}$ thickness. The concrete tube was installed in the stainless steel box filled with sand.

As seen in Figure 3, the heat exchange pipes $(4.5 \mathrm{~mm}$ external diameter and $0.75 \mathrm{~mm}$ thickness) were arranged on the surface of concrete tube. Three kinds of heat exchange pipe arrangements were designed and fixed on the concrete tube with the $5 \mathrm{~cm}$ interval. Each type of pipe arrangement had a width of $30 \mathrm{~cm}$. For type 1, the total length and spacing distance of pipe were $18.5 \mathrm{~m}$ and $2.25 \mathrm{~cm}$, respectively, and the pipe was installed laterally along the concrete tube. For type 2 , the total length and spacing distance of pipe were $19 \mathrm{~m}$ and $2.25 \mathrm{~cm}$, respectively, and the pipe was installed longitudinally along the concrete tube. For type 3 , the total length and spacing distance of pipe were $37 \mathrm{~m}$ and $1.125 \mathrm{~cm}$, respectively, and the pipe was also arranged laterally along the concrete tube. The tunnel model box was filled with the almost homogeneous sand layer according to the sand-raining method $[37,38]$. The Yangtze River sand was chosen in the current study, and the minimum and maximum dry densities of sand were measured as $1.37 \mathrm{~g} / \mathrm{cm}^{3}$ and $1.61 \mathrm{~g} / \mathrm{cm}^{3}$. The relationship between thermal conductivity and water content of sand is shown in Figure 4.

2.3. Experimental Scheme. Three parameters of wind speed, seepage velocity of groundwater, and insulation layer were taken into account in the laboratory model experiment of the energy tunnel. Based on the previous studies [22, 28], the intermittent operation mode was selected in the current test, in which the pump worked from $12 \mathrm{am}$ to $8 \mathrm{pm}$ per day. Therefore, the intermittent ratio was $1: 2$. Based on the previous studies $[8,11,28]$, the sand tank temperature for simulating the temperature of the surrounding rock was set as $20^{\circ} \mathrm{C}$ during the energy tunnel model test, and the inlet temperature of GHEs was set as $35^{\circ} \mathrm{C}$. According to the field test results of Zhang et al. [28], the laboratory model test adopted the condition of uniform ventilation, and the maximum wind velocity was chosen as $4 \mathrm{~m} / \mathrm{s}$. Based on the previous research results of the influence of groundwater seepage [27], the velocity of groundwater flow was set as two levels, that is, $1 \times 10^{-4}$ and $5 \times 10^{-4} \mathrm{~m} / \mathrm{s}$. Moreover, the model tests were performed at the condition of the energy tunnel model with or without the insulation layer. The experimental program of the energy tunnel model is listed in Table 2.

\section{Results and Discussion}

3.1. Temperature Variation of Airflow inside the Tunnel. The temperature variation feature of airflow in the tunnel with the insulation layer at various locations is clearly presented in Figure 5. From Figure 5(a), it is found that the air temperature at center part of the tunnel with the insulation layer varies with elapsed time, which is relatively low compared with the condition of the tunnel without the insulation layer in previous results [28]. The temperature fluctuation of air inside the tunnel at the inner side of the insulation layer (tunnel vault) is illustrated in Figure 5(b), which has a higher 
TABLE 2: The detailed design scheme of thermal response tests of the energy tunnel model.

\begin{tabular}{|c|c|c|c|c|c|c|c|}
\hline \multicolumn{4}{|c|}{$0 \mathrm{~mm}$-thickness insulation layer } & \multicolumn{4}{|c|}{$10 \mathrm{~mm}$-thickness insulation layer } \\
\hline \multicolumn{2}{|c|}{$\begin{array}{l}\text { Groundwater seepage } \\
\text { velocity of } 1 \times 10^{-4} \mathrm{~m} / \mathrm{s}\end{array}$} & \multicolumn{2}{|c|}{$\begin{array}{l}\text { Groundwater seepage } \\
\text { velocity of } 5 \times 10^{-4} \mathrm{~m} / \mathrm{s}\end{array}$} & \multicolumn{2}{|c|}{$\begin{array}{l}\text { Groundwater seepage } \\
\text { velocity of } 1 \times 10^{-4} \mathrm{~m} / \mathrm{s}\end{array}$} & \multicolumn{2}{|c|}{$\begin{array}{c}\text { Groundwater seepage } \\
\text { velocity of } 5 \times 10^{-4} \mathrm{~m} / \mathrm{s}\end{array}$} \\
\hline No. & Wind speed $(\mathrm{m} / \mathrm{s})$ & No. & Wind speed $(\mathrm{m} / \mathrm{s})$ & No. & Wind speed $(\mathrm{m} / \mathrm{s})$ & No. & Wind speed $(\mathrm{m} / \mathrm{s})$ \\
\hline 1 & 0.64 & 6 & 0.55 & 11 & 0.66 & 16 & 0.87 \\
\hline 2 & 0.99 & 7 & 1.19 & 12 & 0.90 & 17 & 1.30 \\
\hline 3 & 1.85 & 8 & 2.39 & 13 & 2.05 & 18 & 2.10 \\
\hline 4 & 3.14 & 9 & 2.82 & 14 & 3.49 & 19 & 2.72 \\
\hline 5 & 3.85 & 10 & 3.76 & 15 & 3.88 & 20 & 3.88 \\
\hline
\end{tabular}

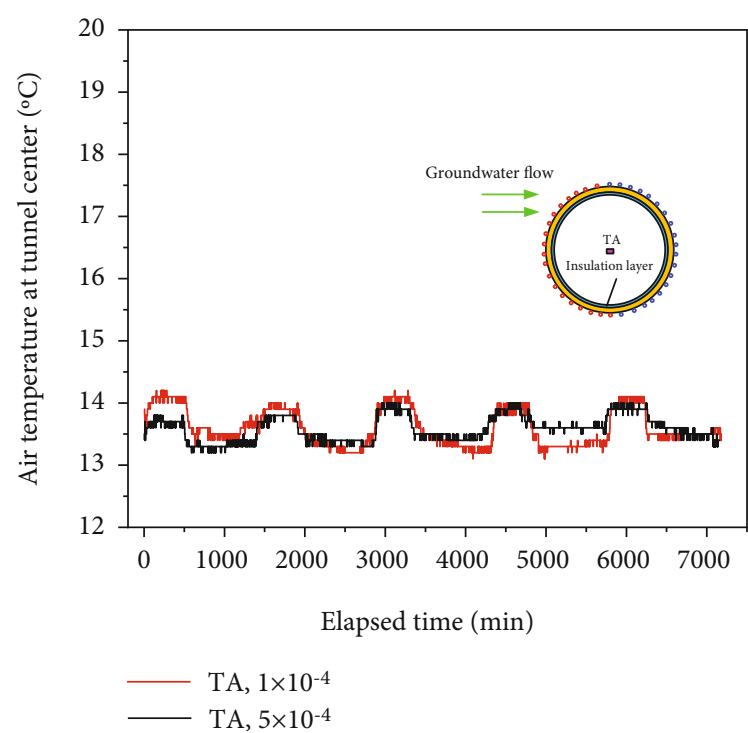

(a) Air temperature at tunnel center

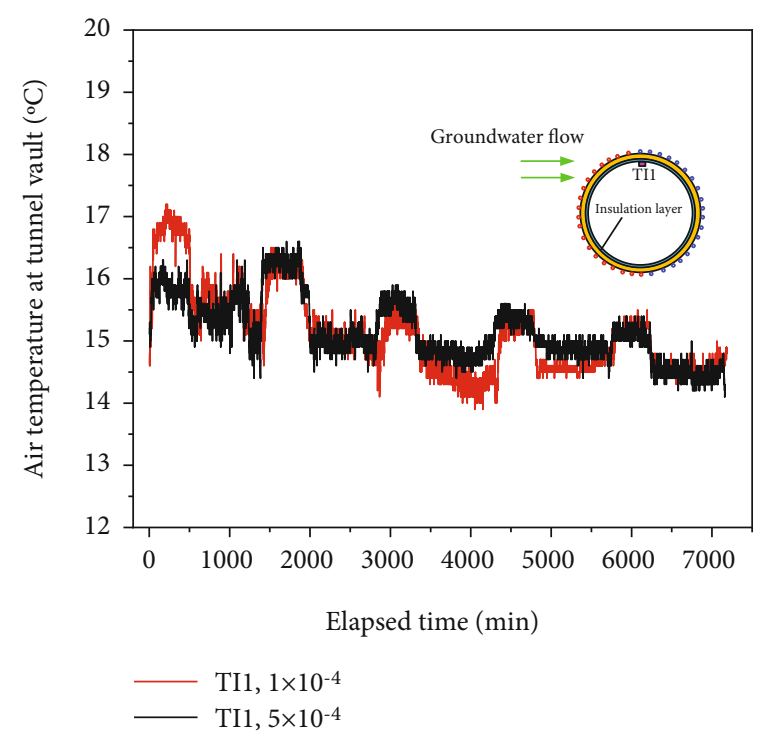

(b) Air temperature at tunnel vault

FiguRE 5: Temperature variation trend of airflow inside the energy tunnel at different locations.

temperature than the air temperature at center part of the energy tunnel. Because the variation of air temperature at tunnel vault is closely relevant to the heat transfer of energy tunnel GHEs, the air temperature at this location possess a relatively high temperature. When the system of the energy tunnel starts to work, the air temperature at the tunnel vault gradually rises. After that, the air temperature maintains within a certain range, and the air temperature decreases as the system of the energy tunnel stops. The temperature fluctuation of airflow within tunnel at different locations can affect each other; thus, the air temperature at center part of the tunnel shows similar variation law. Moreover, the change of the airflow inside the tunnel is affected by the ventilation and groundwater seepage, which is similar to the results of previous studies [26-28].

3.2. Temperature Difference between Tunnel Lining and Airflow. Figure 6 depicts the influence of the insulation layer on the evolution law of temperature difference between tunnel lining as well as the air inside the tunnel under different wind speeds (from 0.64 to $3.85 \mathrm{~m} / \mathrm{s}$, from 0.55 to $3.76 \mathrm{~m} / \mathrm{s}$, from 0.66 to $3.88 \mathrm{~m} / \mathrm{s}$, and 0.87 to $3.88 \mathrm{~m} / \mathrm{s}$ ) and groundwater flow velocities $\left(1 \times 10^{-4}\right.$ and $\left.5 \times 10^{-4} \mathrm{~m} / \mathrm{s}\right)$. As seen in
Figure 6, it is worth noting that the temperature difference of the tunnel model with the insulation layer is larger than that of the tunnel model without the insulation layer at the same groundwater flow velocity and wind speed. From Figure 6, it is found that the temperature difference displays a downward trend with an increase in wind speed, which is in agreement with the results of Zhang et al. [28]. At the groundwater flow velocities of $1 \times 10^{-4}$ and $5 \times 10^{-4} \mathrm{~m} / \mathrm{s}$, the temperature differences of the tunnel model without the insulation layer reduce by $49.27 \%, 53.18 \%, 56.06 \%$, and $56.27 \%$ and $49.53 \%, 52.72 \%, 55.94 \%$, and $55.48 \%$ at the different positions of TL1-TA, TL2-TA, TL3-TA, and TL4-TA as the wind speeds, respectively, rise from 0.64 to $3.85 \mathrm{~m} / \mathrm{s}$ and 0.55 to $3.76 \mathrm{~m} / \mathrm{s}$. The more amount of heat is transmitted from tunnel lining to air due to the increasing wind speed; thus, the temperature of tunnel lining displays a gradually decreasing trend, which can reduce the temperature difference between them [28]. Furthermore, the temperature difference of the tunnel model with the insulation layer presents a relatively slow reduction amplitude with increasing wind speed. At two same seepage velocity of groundwater, the temperature differences of the tunnel model with the insulation layer reduce by $15.70 \%, 14.62 \%, 12.69 \%$, and 

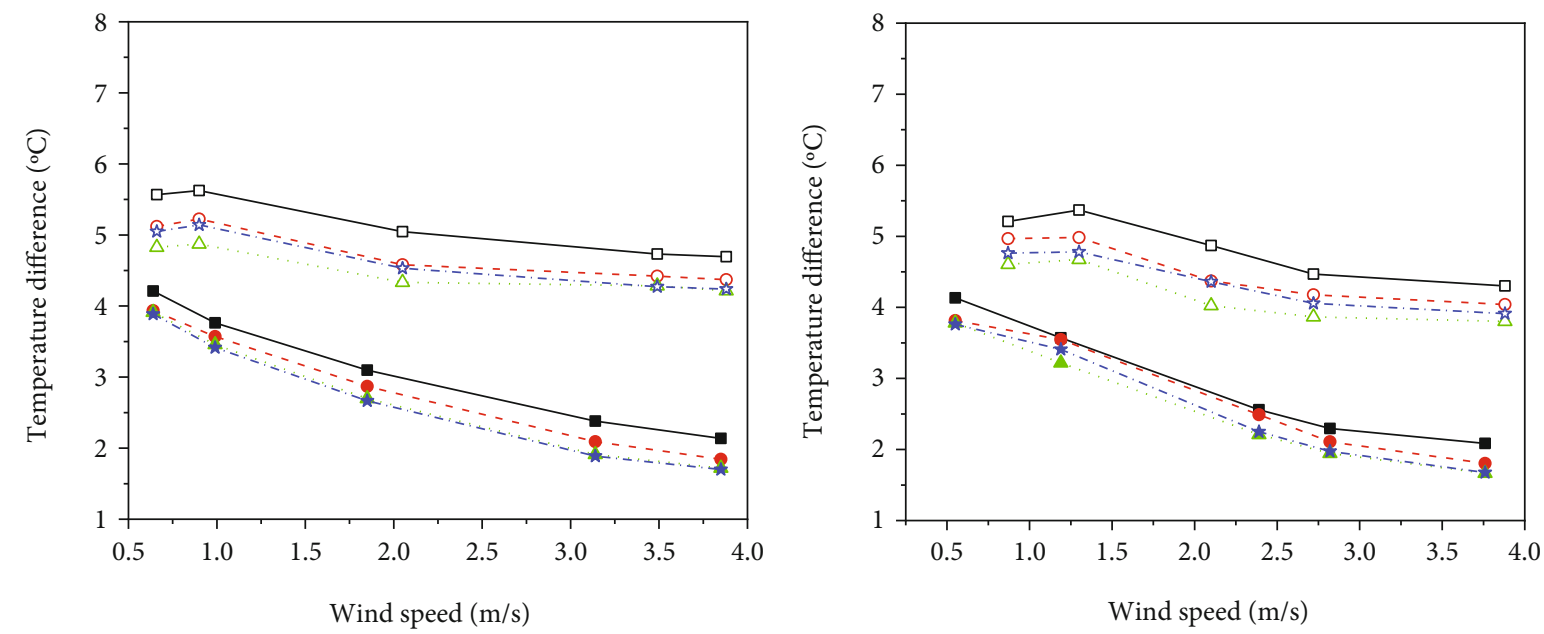

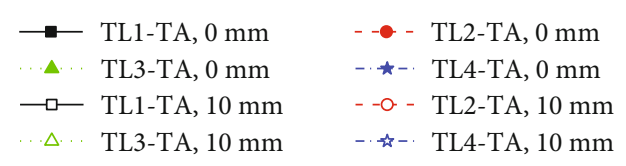

(a) $1 \times 10^{-4} \mathrm{~m} / \mathrm{s}$ groundwater seepage velocity

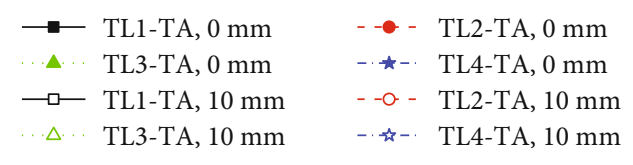

(b) $5 \times 10^{-4} \mathrm{~m} / \mathrm{s}$ groundwater seepage velocity

FIGURE 6: Impact of the insulation layer on the temperature difference variation between tunnel lining and airflow.

$16.03 \%$ and $17.44 \%, 18.65 \%, 17.41 \%$, and $17.87 \%$ for TL1-TA, TL2-TA, TL3-TA, and TL4-TA as the wind speeds, respectively, increase from 0.66 to $3.88 \mathrm{~m} / \mathrm{s}$ and 0.87 to $3.88 \mathrm{~m} / \mathrm{s}$. This is mainly because the impact of tunnel ventilation on the temperature variation is alleviated by the insulation layer, and the existence of the insulation layer keeps the relatively stable temperature of tunnel lining for a period of time due to its preferable heat-insulating property. A comparison of Figures 6(a) and 6(b) indicates that the impact of groundwater flow on the temperature difference between tunnel lining and air is relatively small compared with ventilation.

\subsection{Interface Temperature Variation of Tunnel Lining and} Surrounding Rock. Figure 7 shows the effect of the insulation layer on the temperature variation trend for the interface of tunnel lining and surrounding rock (TS2, TS3, and TS5) at different wind speeds and groundwater flow velocities. It can be clearly found that at the same environmental conditions, the peak interface temperatures of lining and surrounding rock for the tunnel model with the insulation layer at TS2, TS3, and TS5 are larger than that of tunnel model without the insulation layer. It also can be found that the tunnel insulation layer and relatively low wind speed can lead to the higher peak temperature of interface of tunnel lining and surrounding rock at the same other conditions, and the impact of tunnel ventilation on the interface temperature variation is limited for the tunnel with the insulation layer. At TS2 (Figure 7(b)), the peak temperatures, respectively, decrease from 20.4 to $19.9^{\circ} \mathrm{C}, 19.8$ to $19.7^{\circ} \mathrm{C}, 19.8$ to $18.7^{\circ} \mathrm{C}$, and 19.6 to $18.6^{\circ} \mathrm{C}$ as the wind speeds increase from 0.66 to $3.88 \mathrm{~m} / \mathrm{s}$ (with insulation layer and $1 \times 10^{-4} \mathrm{~m} / \mathrm{s}$ seepage velocity), 0.87 to $3.88 \mathrm{~m} / \mathrm{s}$ (with insulation layer and $5 \times$ $10^{-4} \mathrm{~m} / \mathrm{s}$ seepage velocity), 0.64 to $3.85 \mathrm{~m} / \mathrm{s}$ (without insulation layer and $1 \times 10^{-4} \mathrm{~m} / \mathrm{s}$ seepage velocity), and 0.55 to
$3.76 \mathrm{~m} / \mathrm{s}$ (without insulation layer and $5 \times 10^{-4} \mathrm{~m} / \mathrm{s}$ seepage velocity). The similar temperature variation trends are also presented in Figures $7(\mathrm{~d})$ and $7(\mathrm{f})$. The reason is that the insulation layer can reduce the heat loss and sustain the relatively high temperature between tunnel lining and surrounding rock. The ventilation can improve the heat transfer effect and change the temperature between tunnel lining and surrounding rock by increasing the convective heat transfer coefficient [26], the more heat energy is transported from the surrounding rock to tunnel air, and the peak temperature of interface of lining and surrounding rock decreases gradually with an increase in wind speed. However, the impact of ventilation on the interface temperature variation is alleviated when using a tunnel insulation layer.

Comparing Figures 7(a), 7(c), and 7(e), it is observed that the variation of groundwater seepage can produce the interface temperature fluctuation of tunnel lining and surrounding rock. At the upstream section, the lower seepage velocity of groundwater can produce the higher temperature of interface of lining and surrounding rock, while this situation is different at the downstream section. Additionally, the interface temperature variation at TS3 is more obvious than that at TS2 and TS5. This phenomenon indicates that the interface temperature at upstream section (TS2 and TS3) of groundwater flow is susceptible to energy tunnel GHEs compared with the downstream section (TS5). Therefore, the energy tunnel GHEs are suggested to arrange at the upstream section of groundwater seepage due to the better heat exchange effect in upstream section [28]. The seepage direction and velocity of groundwater can remarkably influence the interface temperature variation of lining and surrounding rock caused by the heat exchange of the energy tunnel GHEs $[12,23,27,28]$, which need to be meticulously considered in the layout of the GHEs for obtaining desirable thermal efficiency. 


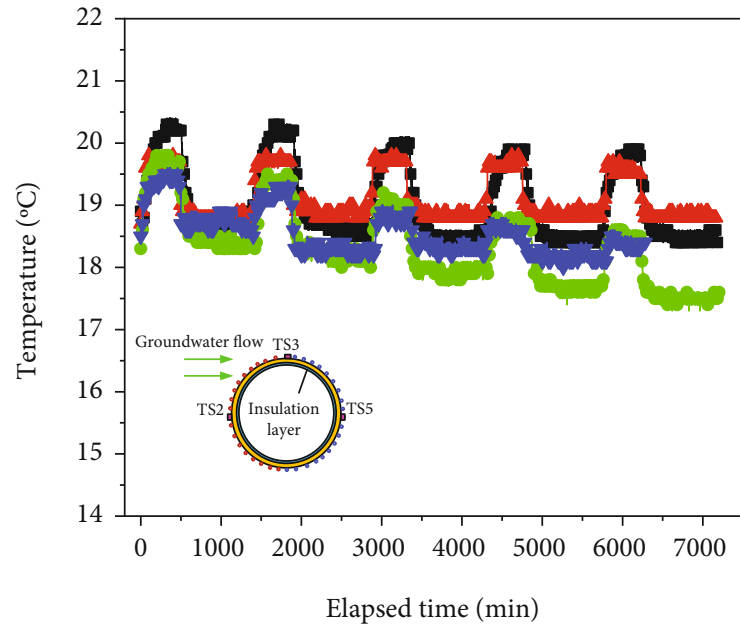

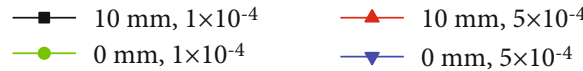

(a) TS2

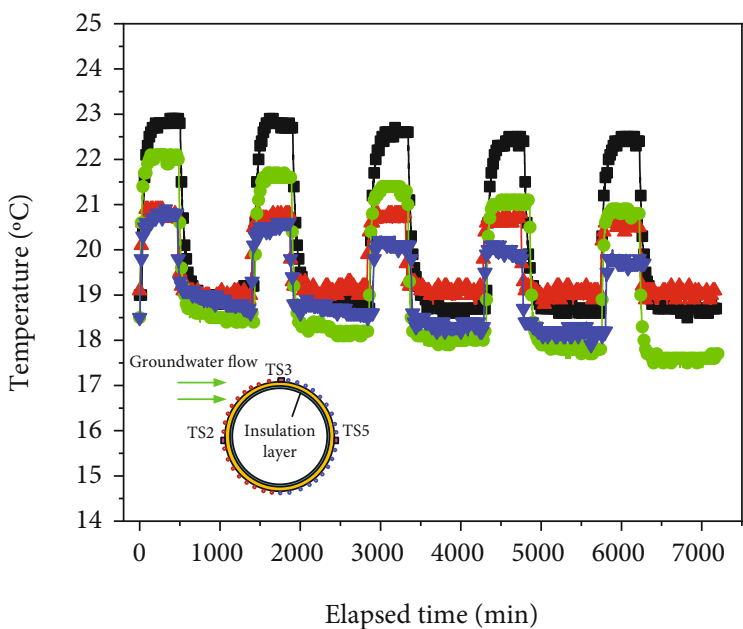

$\longrightarrow 10 \mathrm{~mm}, 1 \times 10^{-4} \longrightarrow 10 \mathrm{~mm}, 5 \times 10^{-4}$

(c) TS3

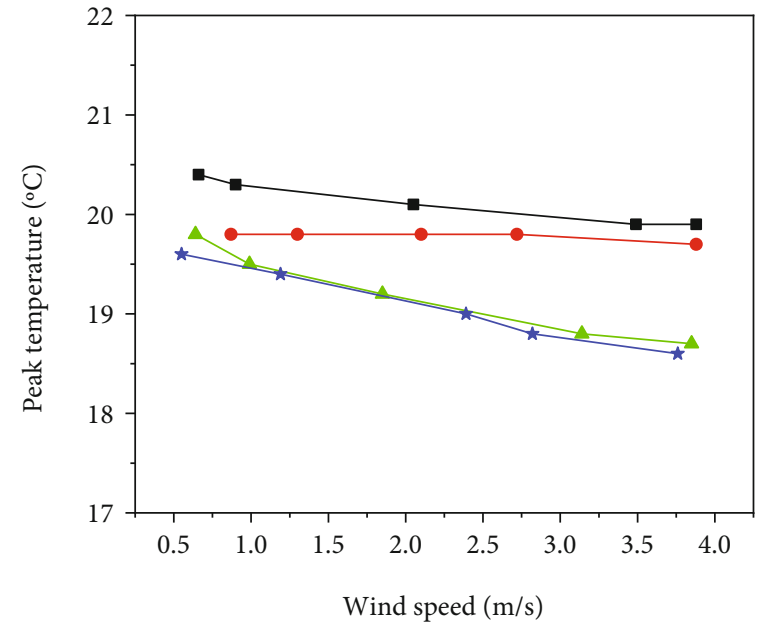

$\longrightarrow-10 \mathrm{~mm}, 1 \times 10^{-4} \quad \longrightarrow 10 \mathrm{~mm}, 5 \times 10^{-4}$

$\leadsto 0 \mathrm{~mm}, 1 \times 10^{-4} \quad$ « $0 \mathrm{~mm}, 5 \times 10^{-4}$

(b) Peak temperature at TS2

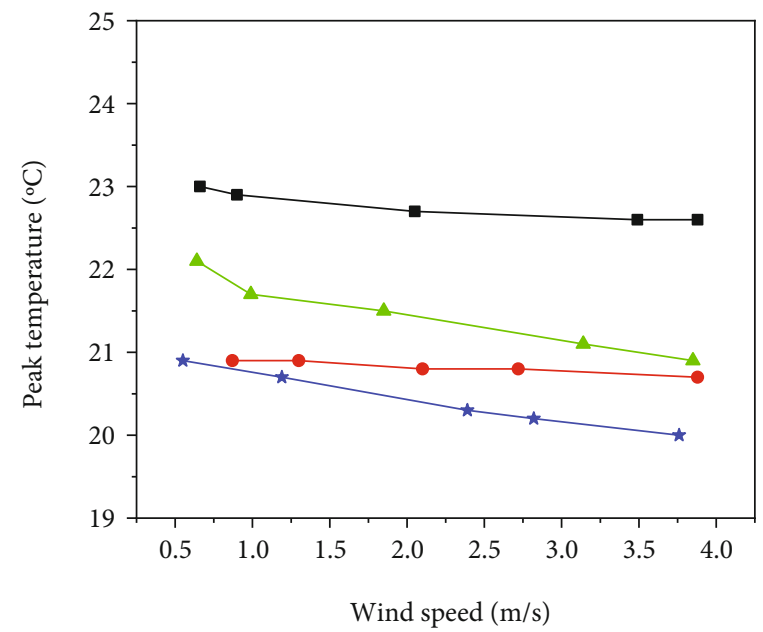

\begin{tabular}{ll}
$\longrightarrow$ & $10 \mathrm{~mm}, 1 \times 10^{-4}$ \\
$\longleftarrow$ & $0 \mathrm{~mm}, 1 \times 10^{-4} \quad \longrightarrow 10 \mathrm{~mm}, 5 \times 10^{-4}$ \\
\hdashline $0 \mathrm{~mm}, 5 \times 10^{-4}$
\end{tabular}

(d) Peak temperature at TS3

Figure 7: Continued. 


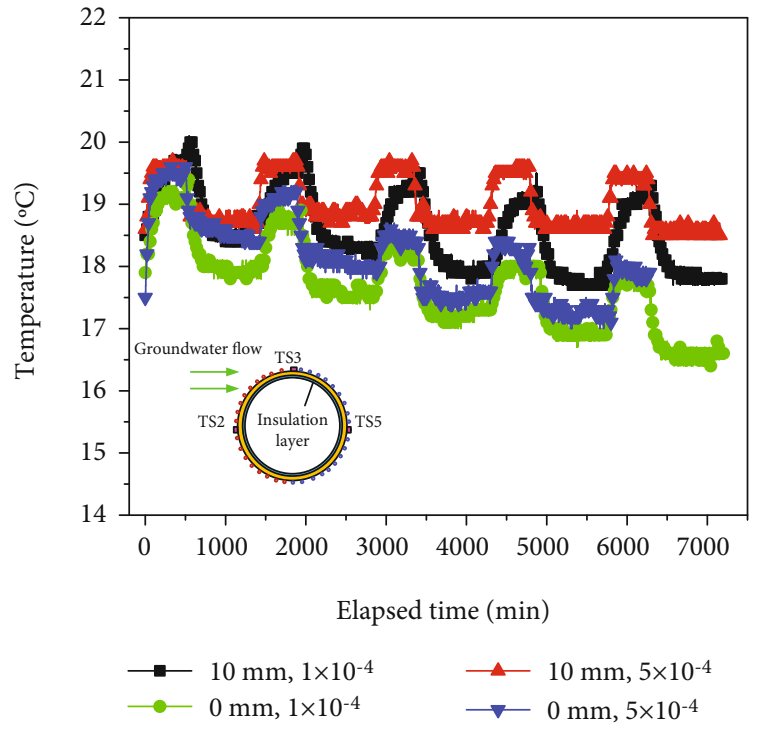

(e) TS5
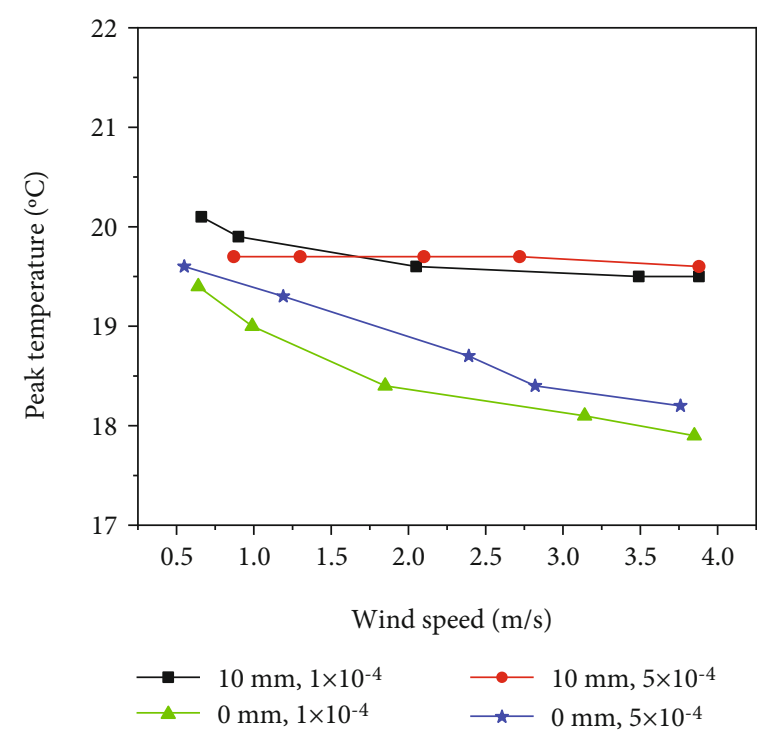

(f) Peak temperature at TS5

FIGURE 7: Influence of the insulation layer on the interface temperature variation between lining and surrounding rock at different locations.

\subsection{Temperature Variation of the Surrounding Rock. Figure 8} illustrates the function of the insulation layer on the temperature variation trend of the surrounding rock at the various seepage velocities and wind speeds. Along the direction parallel to the groundwater seepage, at TS1 (Figure 8(a)), the effects of tunnel ventilation, groundwater flow, and insulation layer on the temperature variation of the surrounding rock both are negligible. At TS6 ((Figure 8(e)) and TS7 (Figure $8(\mathrm{~g})$ ), when the tunnel is not equipped with the insulation layer and seepage velocity is $1 \times 10^{-4} \mathrm{~m} / \mathrm{s}$, the peak ground temperatures, respectively, decrease from 19.7 to $18.6^{\circ} \mathrm{C}$ and from 20 to $19.3^{\circ} \mathrm{C}$ with an increase in wind speed. When the insulation layer is placed inside the energy tunnel, the decreasing amplitude of peak ground temperature with wind speed is relatively small. Besides, the variation of groundwater seepage can change the ground temperature at TS6 and TS7. The above phenomenon indicates that along the direction parallel to the groundwater seepage, the influencing range of energy tunnel GHEs on the variation of temperature field of the surrounding rock is wider in the downstream section of groundwater compared with the upstream section [28]. Because the heat amount caused by the energy tunnel is transferred along the direction of groundwater flow, and the ground temperature at TS1 (belongs to the upstream section at the $15 \mathrm{~cm}$ distance from TS2) shows a slight variation. The heat amount can be directly diffused to the downstream section along the direction of groundwater; thus, the ground temperatures at TS6 and TS7 present the conspicuous fluctuation. Along the direction perpendicular to the groundwater seepage, the ground temperature at TS4 (Figure 8(c)) displays the relatively small fluctuation under the different experimental conditions compared with TS6, which presents that the heat amount caused by energy tunnel is mainly diffused along the direction parallel to the groundwater.
3.5. The Outlet Temperature of Energy Tunnel GHEs. Figure 9 shows the influence of the insulation layer on the outlet temperature of GHEs with elapsed time under different conditions of ventilation and groundwater seepage. At the same seepage velocity and similar wind speed, the outlet temperature of GHEs rises firstly and then tends to be stable (this phase is named as the stable phase) with elapsed time. When the energy tunnel model is equipped with an insulation layer, the outlet temperature of the GHEs is apparently higher than that of the tunnel model without the insulation layer, which indicates that the installation of the insulation layer can slow down the heat exchange process between the GHEs and the air inside the energy tunnel. The final outlet temperature of stable phase for the energy tunnel with or without the insulation layer at various environmental conditions is plotted in Figure 10. It can be found that at the seepage velocities of 1 $\times 10^{-4}$ and $5 \times 10^{-4} \mathrm{~m} / \mathrm{s}$, the final outlet temperature of the energy tunnel without the insulation layer drops significantly with increasing wind speed (Figure 10(a)). However, the final outlet temperature of the energy tunnel with an insulation layer decreases slightly with the wind speed increased from 0.66 to $3.88 \mathrm{~m} / \mathrm{s}$ or 0.87 to $3.88 \mathrm{~m} / \mathrm{s}$. Thus, it is easily concluded that the tunnel ventilation has a less influence on the outlet temperatures of GHEs when using an insulation layer (Figure 10(b)). In addition, it is observed that at the same other conditions, the lower seepage velocity $\left(1 \times 10^{-4} \mathrm{~m} / \mathrm{s}\right)$ can result in the higher final outlet temperature of GHEs.

3.6. Heat Transfer Behavior of Energy Tunnel GHEs. In term of thermal performance analyses for the energy tunnel GHEs, the heat exchange rate is an important indicator. The calculation equation for the total heat exchange rate of energy tunnel GHEs can be determined as:

$$
Q=\rho v c_{p}\left(T_{\text {in }}-T_{\text {out }}\right)
$$




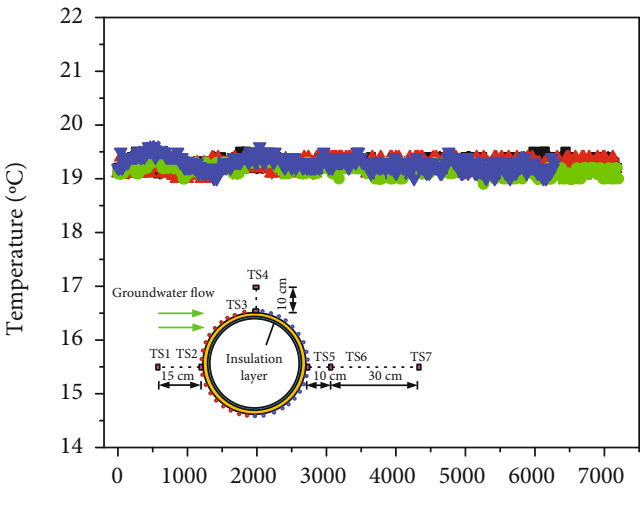

Elapsed time ( $\min )$

$\longrightarrow-10 \mathrm{~mm}, 1 \times 10^{-4} \quad \longrightarrow 10 \mathrm{~mm}, 5 \times 10^{-4}$ $\longrightarrow 0 \mathrm{~mm}, 1 \times 10^{-4} \quad \longrightarrow 0 \mathrm{~mm}, 5 \times 10^{-4}$

(a) TS1

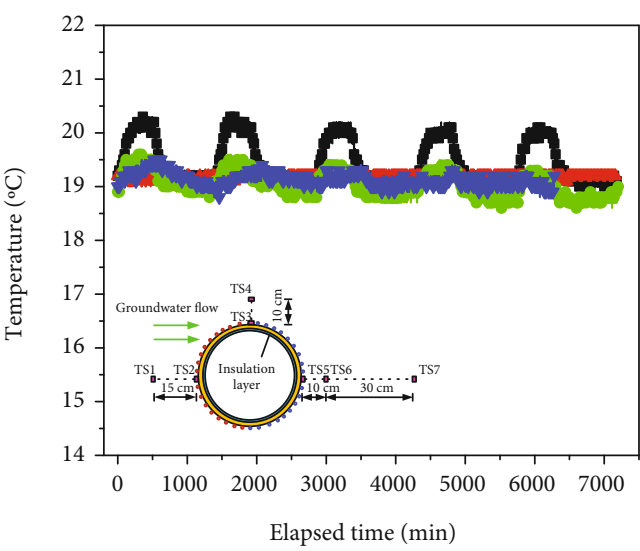

$\longrightarrow-10 \mathrm{~mm}, 1 \times 10^{-4} \quad \longrightarrow 10 \mathrm{~mm}, 5 \times 10^{-4}$ $\longrightarrow 0 \mathrm{~mm}, 1 \times 10^{-4} \quad \longrightarrow 0 \mathrm{~mm}, 5 \times 10^{-4}$

(c) TS4

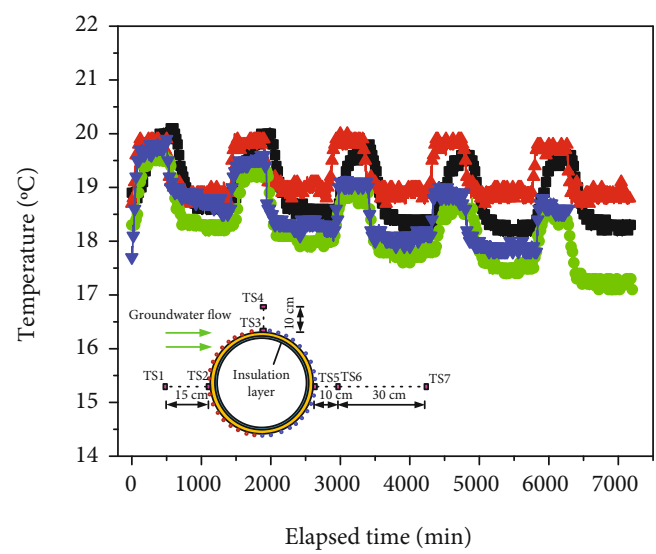

$\longrightarrow 10 \mathrm{~mm}, 1 \times 10^{-4} \longrightarrow 10 \mathrm{~mm}, 5 \times 10^{-4}$

$\longrightarrow 0 \mathrm{~mm}, 1 \times 10^{-4} \quad \longrightarrow 0 \mathrm{~mm}, 5 \times 10^{-4}$

(e) TS6

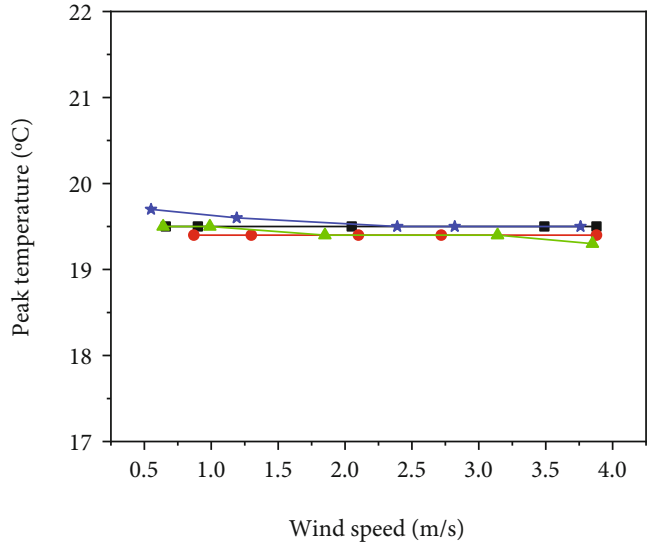

$\rightarrow 10 \mathrm{~mm}, 1 \times 10^{-4} \quad \longrightarrow 10 \mathrm{~mm}, 5 \times 10^{-4}$

- $0 \mathrm{~mm}, 1 \times 10^{-4} \quad$ \# $0 \mathrm{~mm}, 5 \times 10^{-4}$

(b) Peak temperature at TS1

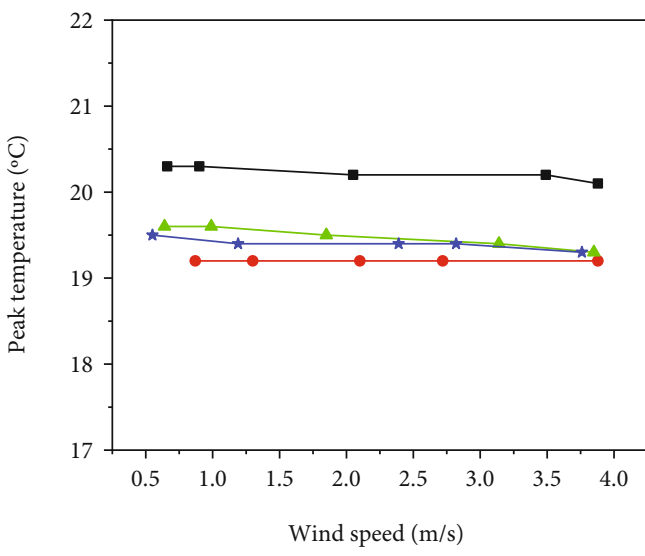

$\rightarrow 10 \mathrm{~mm}, 1 \times 10^{-4} \longrightarrow 10 \mathrm{~mm}, 5 \times 10^{-4}$

$\rightarrow 0 \mathrm{~mm}, 1 \times 10^{-4} \quad$ « $0 \mathrm{~mm}, 5 \times 10^{-4}$

(d) Peak temperature at TS4

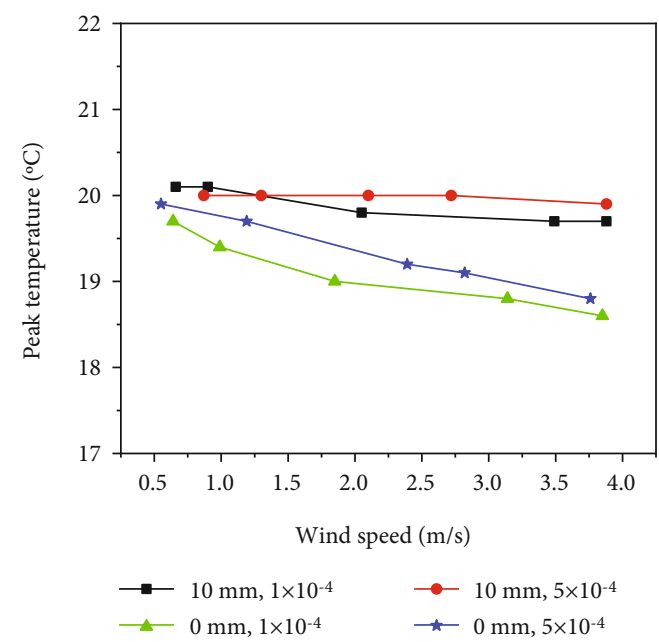

(f) Peak temperature at TS6

Figure 8: Continued. 


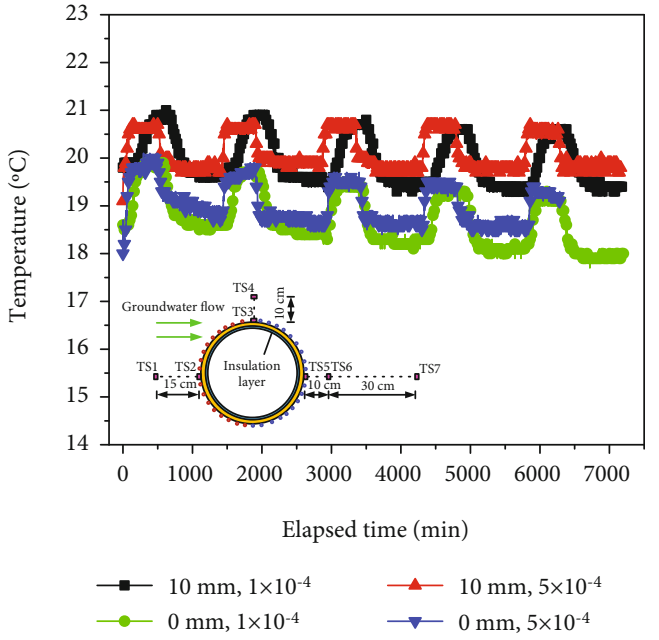

(g) TS7

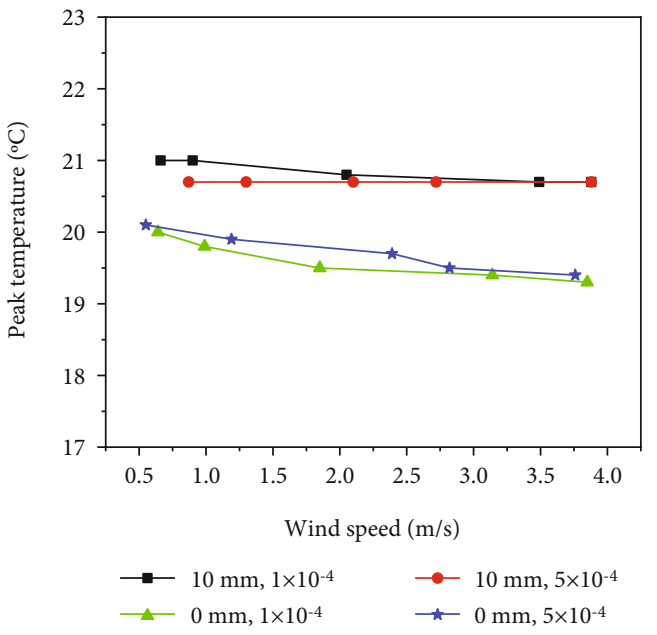

(h) Peak temperature at TS7

FIGURE 8: Influence of the insulation layer on the surrounding rock temperature variation trend at different locations.

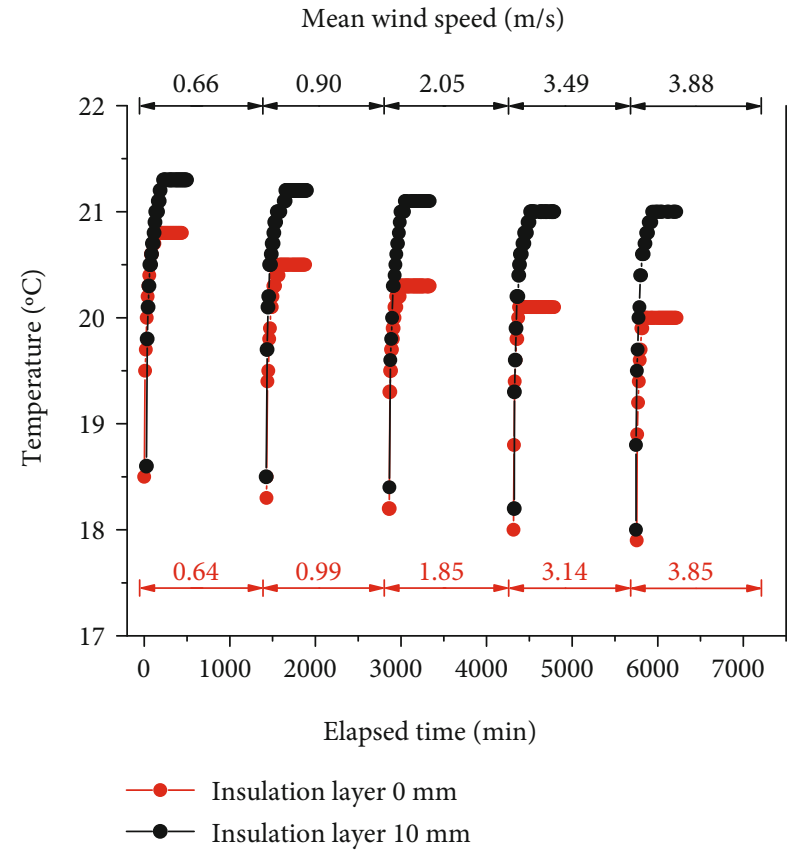

(a) $1 \times 10^{-4} \mathrm{~m} / \mathrm{s}$ groundwater seepage velocity

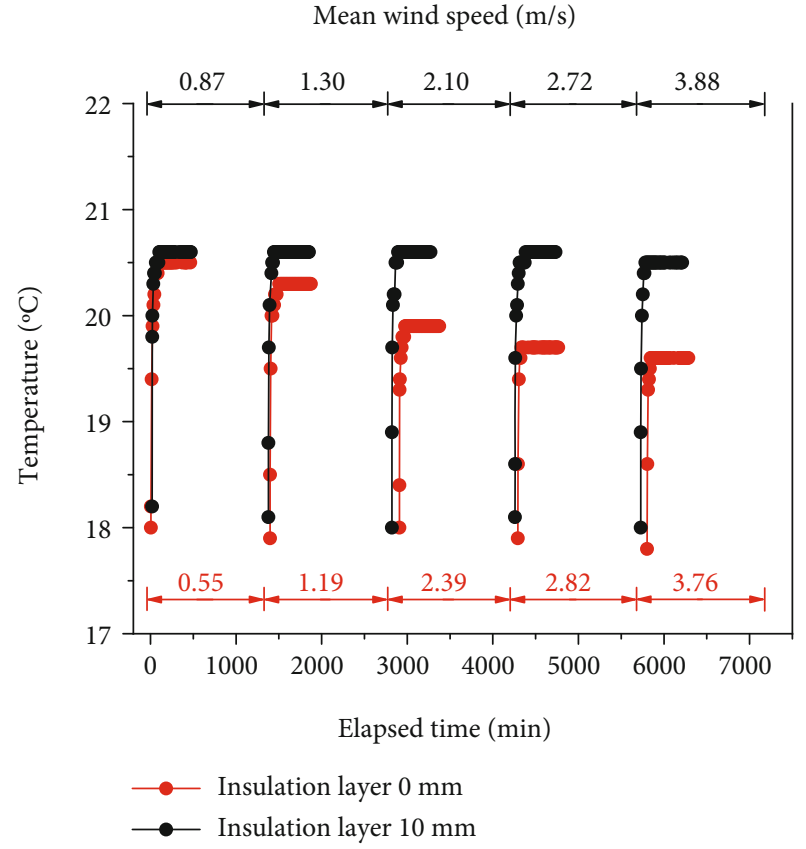

(b) $5 \times 10^{-4} \mathrm{~m} / \mathrm{s}$ groundwater seepage velocity

FIGURE 9: Variation of outlet temperature of GHEs with time for the energy tunnel with or without the insulation layer.

where $Q$ denotes the heat exchange rate of energy tunnel GHEs (W), $\rho$ denotes the density of circulating fluid $\left(\mathrm{kg} / \mathrm{m}^{3}\right), v$ denotes the volume flow rate of circulating fluid $\left(\mathrm{m}^{3} / \mathrm{s}\right), c_{p}$ denotes constant pressure specific heat capacity of circulating fluid $(\mathrm{J} /(\mathrm{kg} \mathrm{K})), T_{\text {in }}$ denotes the inlet temperature of fluid $(\mathrm{K})$, and $T_{\text {out }}$ denotes the outlet temperature of fluid (K).

Figures 11 and 12 demonstrate the changing trend of the heat exchange rate for the energy tunnel with or without the insulation layer at different wind speeds and groundwater flow velocities. In Figure 11(a), when the energy tunnel is not equipped with an insulation layer, the higher wind speed and higher seepage velocity of groundwater both can effectively improve the heat transfer amount, which is similar to the results of previous studies [12, 23, 26-28]. At two groundwater flow velocities, the heat exchange rates enhance by $5.82 \%$ and $6.45 \%$ as the wind speeds, respectively, increase from 0.64 to $3.85 \mathrm{~m} / \mathrm{s}$ and from 0.55 to $3.76 \mathrm{~m} / \mathrm{s}$. However, when the $10 \mathrm{~mm}$-thickness insulation layer is placed inside the energy tunnel (Figure 11(b)) and seepage velocity of groundwater is same, the heat exchange rate has been improved slightly with an increase in wind speed, and the 


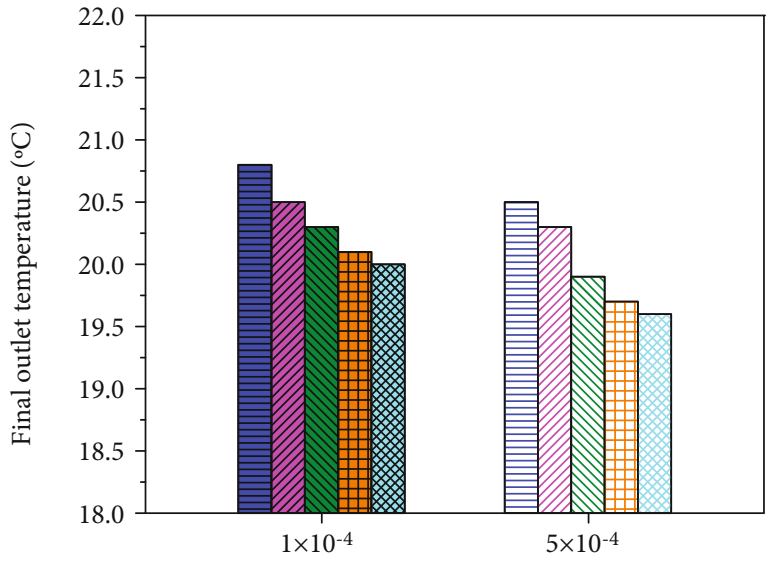

Groundwater seepage velocity $(\mathrm{m} / \mathrm{s})$

\begin{tabular}{|c|c|c|}
\hline & 0.64 & MWV \\
\hline E & 0.55 & 册曲 \\
\hline $\mathbb{Z}$ & 0.99 & 世丑 \\
\hline $\mathbb{Z}$ & 1.19 & \\
\hline & 1.85 & \\
\hline
\end{tabular}

(a) Without the insulation layer

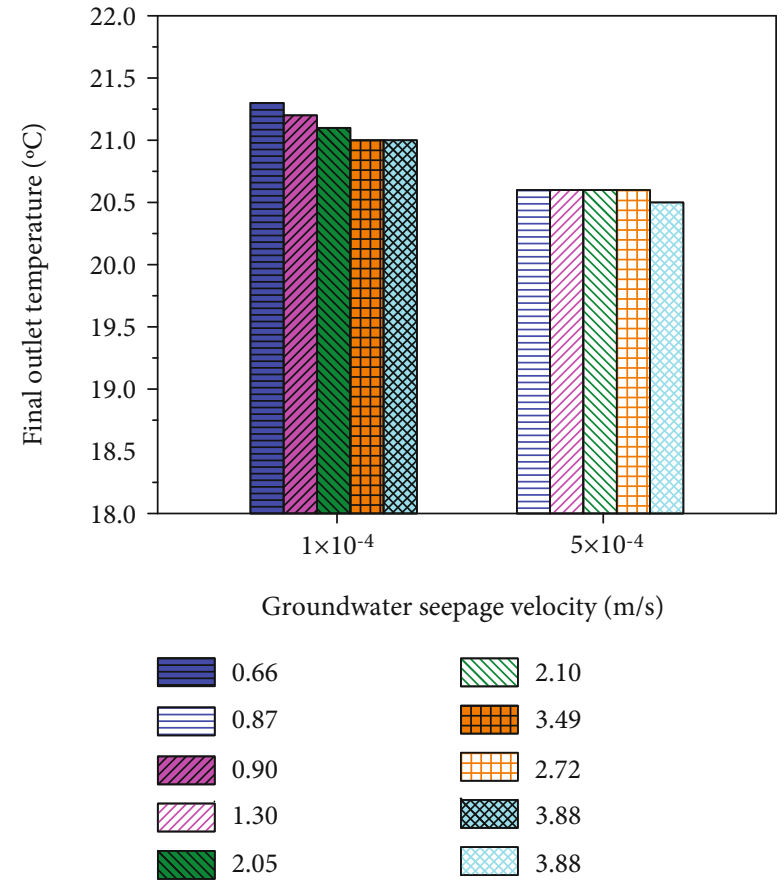

(b) $10 \mathrm{~mm}$-thickness insulation layer

FIGURE 10: Relationship between final outlet temperature of GHEs and groundwater seepage velocity at various wind speeds.

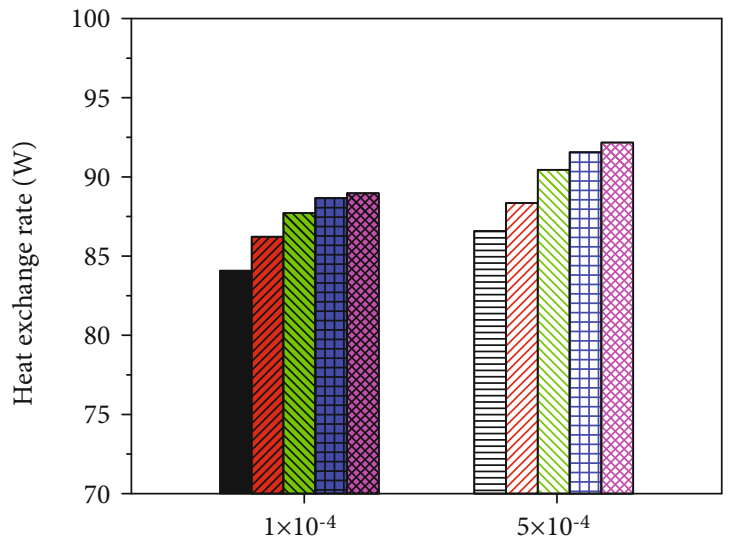

Groundwater seepage velocity $(\mathrm{m} / \mathrm{s})$

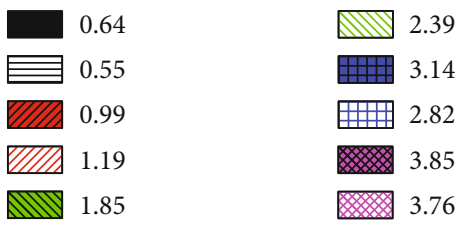

(a) Without insulation layer

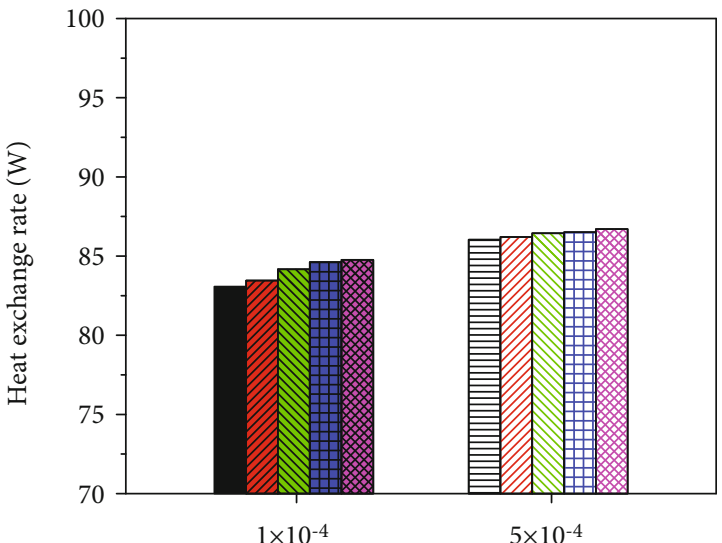

Groundwater seepage velocity $(\mathrm{m} / \mathrm{s})$

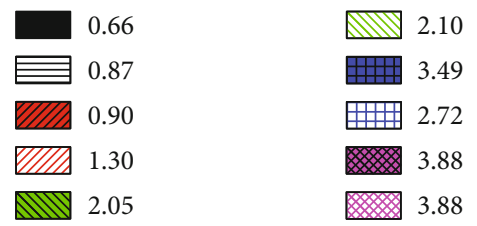

(b) $10 \mathrm{~mm}$-thickness insulation layer

FIGURE 11: Relationship between heat exchange rate and groundwater seepage velocity at various wind speeds.

maximum values of heat exchange rate only increase by $2.03 \%$ and $0.77 \%$. Meanwhile, at the similar wind speed, the groundwater flow both can produce a close improvement effect on the thermal behavior when using or not using the insulation layer. Therefore, the enhancement effect of ventilation on the heat exchange rate is more obvious for the tun- nel without the insulation layer at the same condition of groundwater seepage, while the enhancement effect of groundwater seepage on the heat exchange rate is less related to the insulation layer.

As seen in Figure 12, it is observed that the installation of the insulation layer inside the tunnel can reduce the heat 


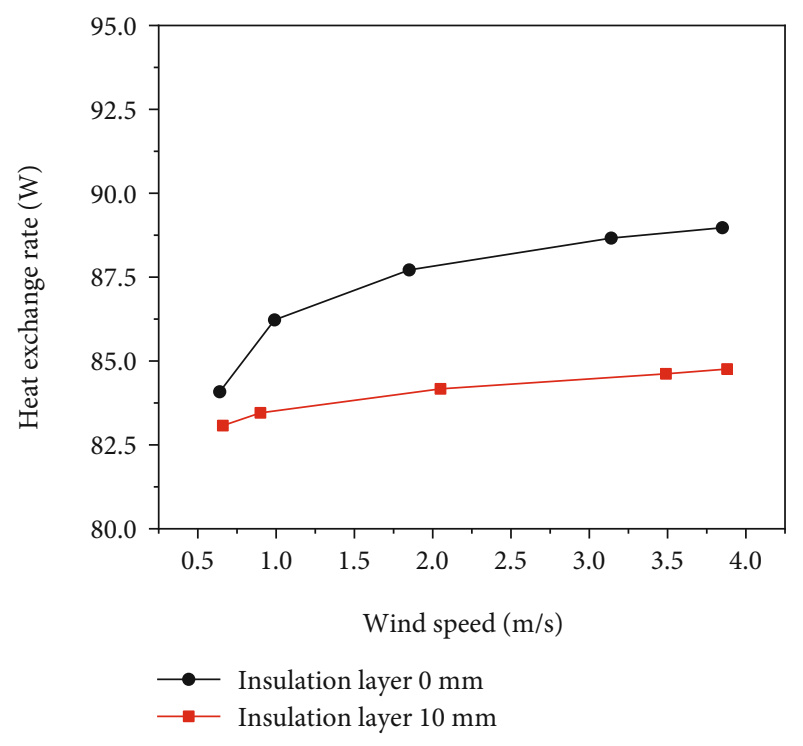

(a) $1 \times 10^{-4} \mathrm{~m} / \mathrm{s}$ groundwater seepage velocity

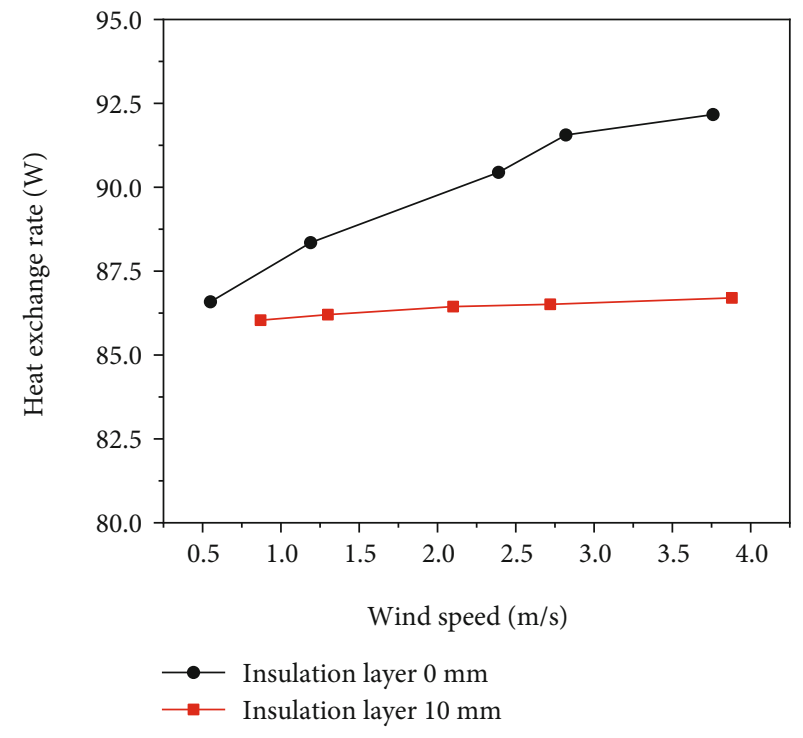

(b) $5 \times 10^{-4} \mathrm{~m} / \mathrm{s}$ groundwater seepage velocity

FIGURE 12: Influence of the insulation layer on the heat exchange rate of energy tunnel GHEs at different environmental conditions.

exchange capacity of energy tunnel GHEs. Besides, at the same seepage velocity of groundwater, the weakening effect of the insulation layer on the heat transfer performance of the energy tunnel becomes increasingly evident as the wind speed is higher. In the current studies, the air inside tunnel is beneficial for the energy tunnel to extract cold energy amount, and the setting of the insulation layer within the tunnel has an adverse influence on the heat exchange process. Thus, the tunnel insulation layer reduces the heat exchange amount of the energy tunnel under the same other conditions. In other words, when the energy tunnel is used to extract heat energy during the winter season, the effect of the insulation layer on the heat transfer performance of the energy tunnel is advantageous.

\section{Conclusions}

The thermal response model experiments were performed to investigate the influence of the insulation layer on the heat transfer potential of the energy tunnel under the environmental factors of tunnel ventilation and groundwater seepage. The main conclusions can be deduced as follows:

(1) The temperature fluctuation of the airflow inside the tunnel is affected by the tunnel insulation layer, ventilation, and groundwater seepage. The tunnel insulation layer can produce a larger temperature difference between the tunnel lining and air inside the tunnel at the same groundwater flow velocity and wind speed

(2) The impact of ventilation on the temperature variation of interface of tunnel lining and surrounding rock is restricted when utilizing an insulation layer. The interface temperature at the upstream section of groundwater flow is more easily affected by the energy tunnel GHEs compared with the downstream section
(3) Along the direction parallel to groundwater seepage, the influencing range of heat exchange of the energy tunnel GHEs, tunnel ventilation, and insulation layer on the temperature variation range of surrounding rock is wider at the downstream section of groundwater flow compared with the upstream section

(4) The insulation layer can significantly rise the outlet temperature of the GHEs, and the tunnel ventilation has a less impact on the outlet temperature of the GHEs when employing an insulation layer inside the energy tunnel

(5) At the two different groundwater flow velocities, the heat exchange rates of the tunnel without the insulation layer improve by $5.82 \%$ and $6.45 \%$ with an increase in wind speed, while the heat exchange rates of the tunnel with the insulation layer only increase by $2.03 \%$ and $0.77 \%$. The results indicate that the enhancement effect of ventilation on the heat transfer behavior of the energy tunnel is more remarkable when not using an insulation layer. However, the enhancement effect of groundwater seepage on the heat transfer behavior of the energy tunnel is less related to the insulation layer

\section{Data Availability}

The data used to support the findings of this study are available from the corresponding author upon request.

\section{Conflicts of Interest}

The authors declare that there is no conflict of interest regarding the publication of this paper. 


\section{Acknowledgments}

This study was supported by the National Natural Science Foundation of China (No. 51778138). The authors would like to thank the model test support from the School of Transportation of Southeast University.

\section{References}

[1] H. Brandl, "Energy foundations and other thermo-active ground structures," Géotechnique, vol. 56, no. 2, pp. 81-122, 2006.

[2] D. Adam and R. Markiewicz, "Energy from earth-coupled structures, foundations, tunnels and sewers," Géotechnique, vol. 59, no. 3, pp. 229-236, 2009.

[3] F. Loveridge, J. S. McCartney, G. A. Narsilio, and M. Sanchez, "Energy geostructures: a review of analysis approaches, in situ testing and model scale experiments," Geomechanics for Energy and the Environment, vol. 22, p. 100173, 2020.

[4] C. C. Xia, M. Sun, G. Z. Zhang, S. G. Xiao, and Y. C. Zou, "Experimental study on geothermal heat exchangers buried in diaphragm walls," Energy and Buildings, vol. 52, pp. 50$55,2012$.

[5] Y. Rui and M. Yin, "Thermo-hydro-mechanical coupling analysis of a thermo-active diaphragm wall," Canadian Geotechnical Journal, vol. 55, no. 5, pp. 720-735, 2018.

[6] M. de Moel, P. M. Bach, A. Bouazza, R. M. Singh, and J. L. O. Sun, "Technological advances and applications of geothermal energy pile foundations and their feasibility in Australia," Renewable and Sustainable Energy Reviews, vol. 14, no. 9, pp. 2683-2696, 2010.

[7] L. Laloui, M. Nuth, and L. Vulliet, "Experimental and numerical investigations of the behaviour of a heat exchanger pile," International Journal for Numerical and Analytical Methods in Geomechanics, vol. 30, no. 8, pp. 763-781, 2006.

[8] P. J. Bourne-Webb, B. Amatya, K. Soga, T. Amis, C. Davidson, and P. Payne, "Energy pile test at Lambeth college, London: geotechnical and thermodynamic aspects of pile response to heat cycles," Géotechnique, vol. 59, no. 3, pp. 237-248, 2009.

[9] G. Z. Zhang, C. C. Xia, M. Sun, Y. C. Zou, and S. G. Xiao, “A new model and analytical solution for the heat conduction of tunnel lining ground heat exchangers," Cold Regions Science and Technology, vol. 88, pp. 59-66, 2013.

[10] G. Z. Zhang, C. C. Xia, Y. Yang, M. Sun, and Y. C. Zou, "Experimental study on the thermal performance of tunnel lining ground heat exchangers," Energy and Buildings, vol. 77, pp. 149-157, 2014.

[11] M. Barla, A. Di Donna, and A. Insana, "A novel real-scale experimental prototype of energy tunnel," Tunnelling and Underground Space Technology, vol. 87, pp. 1-14, 2019.

[12] M. Barla, A. Di Donna, and A. Perino, "Application of energy tunnels to an urban environment," Geothermics, vol. 61, pp. 104-113, 2016.

[13] C. Lee, S. Park, J. Won, J. Jeoung, B. Sohn, and H. Choi, "Evaluation of thermal performance of energy textile installed in Tunnel," Renewable Energy, vol. 42, pp. 11-22, 2012.

[14] J. N. Franzius and N. Pralle, "Turning segmental tunnels into sources of renewable energy," Proceedings of ICE - Civil Engineering, vol. 164, no. 1, pp. 35-40, 2011.
[15] S. Frodl, J. N. Franzius, and T. Bartl, "Design and construction of the tunnel geothermal system in Jenbach /," Geomechanics and Tunnelling, vol. 3, no. 5, pp. 658-668, 2010.

[16] B. Cousin, A. F. Rotta Loria, A. Bourget, F. Rognon, and L. Laloui, "Energy performance and economic feasibility of energy segmental linings for subway tunnels," Tunnelling and Underground Space Technology, vol. 91, p. 102997, 2019.

[17] P. Buhmann, C. Moormann, B. Westrich, N. Pralle, and W. Friedemann, "Tunnel geothermics-a German experience with renewable energy concepts in tunnel projects," Geomechanics for Energy and the Environment, vol. 8, pp. 1-7, 2016.

[18] A. Bidarmaghz, G. A. Narsilio, P. Buhmann, C. Moormann, and B. Westrich, "Thermal interaction between tunnel ground heat exchangers and borehole heat exchangers," Geomechanics for Energy and the Environment, vol. 10, pp. 29-41, 2017.

[19] A. Revesz, I. Chaer, J. Thompson, M. Mavroulidou, M. Gunn, and G. Maidment, "Ground source heat pumps and their interactions with underground railway tunnels in an urban environment: a review," Applied Thermal Engineering, vol. 93, pp. 147-154, 2016.

[20] G. Z. Zhang, C. C. Xia, M. Sun, Y. C. Zou, and F. Zhao, “Temperature fields analysis of absorbing section of tunnel heating system using heat pump in cold region," Chinese Journal of Rock Mechanics and Engineering, vol. 31, pp. 3795-3802, 2012.

[21] C. Lee, S. Park, H. J. Choi, I. M. Lee, and H. Choi, "Development of energy textile to use geothermal energy in tunnels," Tunnelling and Underground Space Technology, vol. 59, pp. 105-113, 2016.

[22] O. Ogunleye, R. M. Singh, F. Cecinato, and J. C. Choi, "Effect of intermittent operation on the thermal efficiency of energy tunnels under varying tunnel air temperature," Renewable Energy, vol. 146, pp. 2646-2658, 2020.

[23] A. Insana and M. Barla, "Experimental and numerical investigations on the energy performance of a thermo-active tunnel," Renewable Energy, vol. 152, pp. 781-792, 2020.

[24] T. Mimouni, F. Dupray, and L. Laloui, "Estimating the geothermal potential of heat-exchanger anchors on a cut-andcover tunnel," Geothermics, vol. 51, pp. 380-387, 2014.

[25] G. Z. Zhang, C. C. Xia, X. G. Ma, P. Li, and Q. Wei, "Rock-soil thermal response test of tunnel heating system using heat pump in cold region," Chinese Journal of Rock Mechanics and Engineering, vol. 31, no. 1, pp. 99-105, 2012.

[26] G. Z. Zhang, C. C. Xia, X. Zhao, and S. W. Zhou, "Effect of ventilation on the thermal performance of tunnel lining GHEs," Applied Thermal Engineering, vol. 93, pp. 416-424, 2016.

[27] G. Z. Zhang, Y. M. Guo, Y. Zhou et al., "Experimental study on the thermal performance of tunnel lining GHE under groundwater flow," Applied Thermal Engineering, vol. 106, pp. 784795, 2016.

[28] G. Z. Zhang, S. Y. Liu, X. Zhao et al., "The coupling effect of ventilation and groundwater flow on the thermal performance of tunnel lining GHEs," Applied Thermal Engineering, vol. 112, pp. 595-605, 2017.

[29] A. Bidarmaghz and G. A. Narsilio, "Heat exchange mechanisms in energy tunnel systems," Geomechanics for Energy and the Environment, vol. 16, pp. 83-95, 2018.

[30] J. X. Lai, X. L. Wang, J. L. Qiu et al., "A state-of-the-art review of sustainable energy based freeze proof technology for coldregion tunnels in China," Renewable and Sustainable Energy Reviews, vol. 82, pp. 3554-3569, 2018. 
[31] X. F. Zhang, Y. M. Lai, W. B. Yu, and S. J. Zhang, "Nonlinear analysis for the three-dimensional temperature fields in cold region tunnels," Cold Regions Science and Technology, vol. 35, no. 3, pp. 207-219, 2002.

[32] G. Z. Zhang, Z. M. Cao, W. Wang et al., "Field test and numerical investigation on thermal environment of tunnel with air layer structure," Building and Environment, vol. 203, p. 108105, 2021.

[33] X. J. Tan, W. Z. Chen, D. S. Yang et al., "Study on the influence of airflow on the temperature of the surrounding rock in a cold region tunnel and its application to insulation layer design," Applied Thermal Engineering, vol. 67, no. 1-2, pp. 320-334, 2014.

[34] X. H. Zhou, Y. H. Zeng, and L. Fan, “Temperature field analysis of a cold-region railway tunnel considering mechanical and train-induced ventilation effects," Applied Thermal Engineering, vol. 100, pp. 114-124, 2016.

[35] X. H. Zhou, Y. H. Zeng, L. Fan, and X. J. Zhou, “Temporal-spatial evolution laws of temperature field in cold region tunnel and temperature control measures," China Railway Science, vol. 37, no. 3, pp. 46-52, 2016.

[36] Q. G. Ma, X. X. Luo, Y. M. Lai, F. J. Niu, and J. Q. Gao, "Numerical investigation on thermal insulation layer of a tunnel in seasonally frozen regions," Applied Thermal Engineering, vol. 138, pp. 280-291, 2018.

[37] N. S. Rad and M. T. Tumay, "Factors affecting sand specimen preparation by raining," Geotechnical Testing Journal, vol. 10, no. 1, pp. 31-37, 1987.

[38] S. Yoon, S. R. Lee, and G. H. Go, "Evaluation of thermal efficiency in different types of horizontal ground heat exchangers," Energy and Buildings, vol. 105, pp. 100-105, 2015. 